\title{
Premorbid intelligence and brain injury
}

\author{
Paul Graham Morris ${ }^{*}$, J. T. Lindsay Wilson², Laurence T. Dunn ${ }^{3}$ \\ and Graham M. Teasdale ${ }^{3}$ \\ 'Section of Clinical and Health Psychology, University of Edinburgh, UK \\ ${ }^{2}$ Department of Psychology, University of Stirling, UK \\ ${ }^{3}$ Department of Neurosurgery, University of Glasgow, UK
}

\begin{abstract}
Objectives. To determine whether NART scores are associated with severity of brain injury and therefore presumably affected by brain injury. In addition, to compare the Cambridge Contextual Reading Test (CCRT) with injury severity in head-injured individuals.
\end{abstract}

Design and methods. Participants were 55 survivors of traumatic head injury, who completed the NART and the CCRT. The scores on these premorbid measures were then compared with indices of injury severity from their initial neurosurgical admission.

Results. The NART was significantly correlated with Glasgow coma scale, with greater severity of injury associated with poorer performance. Poorer NART performance was also significantly more likely amongst those whose injury resulted in coma. The CCRT was preferred by patients, though it was also significantly associated with Glasgow coma scale and presence of coma.

Conclusions. The data suggest that performance on both the NART and the CCRT are affected by brain injury severity and thus may underestimate true premorbid ability in these individuals. Similar findings would be likely with the conceptually identical WTAR measure. These measures should be used with appropriate caution and may be usefully supplemented by predictions based on demographic information.

The National Adult Reading Test (NART), which assesses the pronunciation of 50 irregularly spelt words, is widely used as an estimate of an individual's intelligence before the onset of dementia or other neurological insult (Nelson \& Willison, 1991). Such measures of premorbid intelligence must correlate highly with measured IQ in the healthy population and be resistant to neurological or psychiatric disorder. The use of the NART as a measure of premorbid intelligence was initially based upon the observation that reading ability is relatively well preserved in individuals with dementia (Nelson \& McKenna, 1975), but the NART has become used as the standard measure of premorbid intelligence across a range of neuropsychiatric conditions

\footnotetext{
* Correspondence should be addressed to Paul Graham Morris, Section of Clinical and Health Psychology, Kennedy Tower, Royal Edinburgh Hospital EHIO 5HF, UK (e-mail: p.g.morris@ed.ac.uk).
} 
(O'Carroll, 1995). The more recent Wechsler Test of Adult Rending (WTAR) is a very similar premorbid measure based upon the same concept as the NART.

Its role as a valid measure of premorbid intelligence following closed head injury has been supported by two studies, which found no significant differences in NART performance between head-injured patients and well-matched controls (Crawford, Parker, \& Besson, 1988; Watt \& O'Carroll, 1999). Additionally, a case study in which the NART error score of a patient was reported to be consistent with an intelligence test conducted 7 years prior to a severe head injury is often cited as support for the use of the NART following head injury (Moss \& Dowd, 1991).

However, there are reasons to question the use of the NART. It has been shown to be compromised in moderate to late stage dementia and in other neurological conditions, including Korsakoff's syndrome (O'Carroll, Moffoot, Ebmeier, \& Goodwin, 1992). Moreover, the studies that support the use of the NART have been based upon relatively small numbers of head-injured individuals and thus may have been unable to detect impairments in NART performance that only affected a minority of these individuals. In view of the heterogeneity of injury severity and lesion location typical of brain injured populations, it is reasonable to suppose that NART performance may be impaired in some individuals and not others. This notion is supported by a study in which actual NART performance was found to be impaired in $30 \%$ of individuals with a brain injury, relative to estimates of NART performance based upon demographic data (Freeman, Godfrey, Harris, \& Partridge, 2001).

Beardsall and Huppert (1994) reasoned that failure to correctly pronounce NART words may sometimes be due to the unusual presentation of the word rather than being due to unfamiliarity with the word. They developed the Cambridge Contextual Reading Task (CCRT), in which the NART words are placed into a series of sentences so that they are presented in a meaningful context rather than in isolation. The provision of contextual cues should facilitate correct word recognition if a lexical entry is present for the word and thus enable a more valid estimation of premorbid ability (Beardsall, 1998). An initial study that supported the use of the CCRT reported that this measure was resistant to the effects of head injury (Watt \& O'Carroll, 1999). However, this study involved only 25 head-injured individuals and one measure of injury severity. We report a comparison of performance on both the NART and CCRT with indices of injury severity in 55 individuals who have suffered a head injury some years previously.

\section{Method}

The study involved individuals who had suffered head injury and were assessed as part of a long-term neuropsychological follow-up project. These participants were drawn from a sample of 94 patients for whom clinical data from the time of injury and some outcome data at 6 months post injury was available. A total of 62 patients participated in follow-up neuropsychological assessments. Non-participation was for the following reasons: no reply from patient (15); unable to contact or establish current GP (10); verified death or serious illness (4); patient declined to participate (3). The NART was not administered if patients reported or demonstrated signs of either dyslexia or visual impairment that hindered their reading ability. These requirements excluded seven patients, leaving a study group comprising 55 head-injury patients. All had been admitted to a regional neurosurgical unit for management in the acute stage. 


\section{Participants}

The head-injury group had a mean age at assessment of 36.6 years $(S D=10.9)$ ranging from 24 to 67 . The mean time between injury and assessment was 7.1 years $(S D=0.8)$, with a range of 5.7-8.9 years. Ages at injury were between 17 and 59. Clinical data describing indices of initial injury severity are outlined in Table 1. Five participants had a history of dysphasia being present at 6 months post injury that had since resolved, and 19 participants had a history of a significant left hemisphere lesion. Participants completed the NART followed by the CCRT as part of their neuropsychological assessment. Previous studies have indicated no significant order effect with these tasks (Conway \& O'Carroll, 1997).

Table I. Indices of head injury severity - number and percentage by group

\begin{tabular}{|c|c|c|c|}
\hline \multicolumn{2}{|c|}{$\begin{array}{l}\text { Glasgow coma scale at A\&E } \\
\text { (Teasdale, 1995) }\end{array}$} & \multicolumn{2}{|l|}{$\begin{array}{l}\text { Post-traumatic amnesia severity } \\
\text { (Teasdale \& Brooks, 1985) }\end{array}$} \\
\hline Severe (GCS 3-8) & $18(33)$ & Extremely Severe (over 4 weeks) & $7(13)$ \\
\hline Moderate (GCS 9-12) & $12(22)$ & Very Severe (I to 4 weeks) & $14(25)$ \\
\hline Mild (GCS I3/I4) & $15(27)$ & Severe (I to 7 days) & $23(42)$ \\
\hline Minor (GCS I5) & $10(18)$ & Mild to moderate $(<24$ hours $)$ & II (20) \\
\hline Significant haematoma & & Ever in coma ${ }^{\dagger}$ & \\
\hline Yes & $30(55)$ & Yes & $26(47)$ \\
\hline No & $25(45)$ & No & $26(47)$ \\
\hline
\end{tabular}

A\&E: Accident and Emergency; GCS: Glasgow coma scale; 't: Unknown for three patients.

Percentage by group in parentheses.

\section{Results}

NART and CCRT error scores were generally higher amongst those with greater injury severity (Table 2). Initial analysis indicated that age at injury was associated with Glasgow coma scale ( $r s=.264, p=.05$ ) and thus was associated with injury severity. As age is also a demographic predictor of NART error scores, in order to control for the possibility that associations between error scores and injury severity were simply due to age, subsequent analyses used partial correlations and analysis of covariance to control for age at injury.

NART performance was significantly correlated with Glasgow coma scale $\left(r_{\text {partial }}=-.305, \quad p=.012\right)$, but not with post-traumatic amnesia severity $\left(r_{\text {partial }}=.202, p=.071\right)$. Those with a significant haematoma made more NART errors, though this was not statistically significant. The presence of coma at any stage was significantly associated with worse NART performance, $F(1,49)=5.62, p=.022$, with an effect size of 0.73 , though the relationship with coma at first admission was not significant.

CCRT scores were also significantly correlated with measures of head injury severity, although the strength of relationship was generally less pronounced. Thus, CCRT error scores were significantly correlated with admission Glasgow coma scale $\left(r_{\text {partial }}=-.275, p=.021\right)$, but not with post-traumatic amnesia $\left(r_{\text {partial }}=.224\right.$, $p=.056)$. Differences in strength of correlation with injury severity between CCRT and NART scores were not statistically significant. Those with a significant haematoma made more CCRT errors, although this was not statistically significant. Both presence of 
Table 2. Injury severity and mean (SD) of error scores on premorbid measures

\begin{tabular}{|c|c|c|c|c|c|}
\hline \multicolumn{3}{|c|}{ Glasgow coma scale at A\&E } & \multicolumn{3}{|c|}{ PTA severity grouping } \\
\hline & NART & CCRT & & NART & CCRT \\
\hline Severe & $28.7(8.6)$ & $26.8(7.9)$ & Extremely severe & $27.9(7.2)$ & $25.7(7.4)$ \\
\hline Moderate & $26.3(8.9)$ & $21.9(8.2)$ & Very severe & $25.3(9.3)$ & $22.6(7.9)$ \\
\hline Mild & $24.0(I I .3)$ & $21.9(8.8)$ & Severe & $26.2(9.7)$ & $24.0(8.4)$ \\
\hline Minor & $19.0(5.5)$ & $17.9(6.0)$ & Mild moderate & $20.8(10.1)$ & $18.9(8.8)$ \\
\hline \multicolumn{3}{|c|}{ Significant haematoma } & \multicolumn{3}{|l|}{ Ever in coma } \\
\hline & NART & CCRT & & NART & CCRT \\
\hline Yes & $26.6(10.4)$ & $23.7(8.6)$ & Yes & $28.0(8.7)$ & $25.2(8.0)$ \\
\hline No & $23.3(8.0)$ & $21.8(8.0)$ & No & $21.5(9.0)$ & $20.0(8.1)$ \\
\hline \multicolumn{3}{|c|}{ Significant left hemisphere lesion } & \multicolumn{3}{|c|}{ History of dysphasia at 6 months } \\
\hline & NART & CCRT & & NART & CCRT \\
\hline Yes & $26.8(10.1)$ & $24.6(8.8)$ & Yes & $23.6(10.2)$ & $20.6(10.7)$ \\
\hline No & $24.2(9.1)$ & $21.9(8.0)$ & No & $25.3(9.5)$ & $23.1(8.2)$ \\
\hline
\end{tabular}

A\&E: Accident \& Emergency; PTA: Post-traumatic amnesia; NART: National Adult Reading Test; CCRT: Cambridge Contextual Reading Task.

coma at first admission, $F(1,52)=4.65, p=.036$, and presence of coma at any stage, $F(1,49)=4.46, p=.040$, were significantly associated with worse CCRT performance, with effect sizes of 0.78 and 0.65 , respectively.

History of dysphasia present at 6 months post injury was not associated with greater error scores. Those with a history of significant left hemisphere lesion made slightly more errors than those without such lesions, but this difference was not significant (Table 2).

Participants made significantly fewer errors on the CCRT than on the NART (paired $t=6.75, p<.001$ ), though healthy participants would also be expected to make fewer errors on the CCRT. As expected, the correlation between NART and CCRT errors was very high $(r=.95, p<.001)$. When asked to indicate a preference for either task, $69 \%$ of patients preferred the CCRT, $11 \%$ preferred the NART, and $20 \%$ had no preference.

\section{Discussion}

Our findings show that performance on the NART is significantly associated with clinical measures of the severity of brain damage following traumatic head injury. Although we cannot rule out the possibility that those who were more severely injured were less intelligent, the results are more likely to indicate that performance on the NART is affected by brain injury in at least some patients. Therefore, reliance on the NART may result in an underestimation of premorbid ability and in an underestimation of the deleterious cognitive effects of the brain injury. As the WTAR measure is based upon the same principles as the NART, it is reasonable to assume that it would also be compromized by brain injury. Although this effect is most pronounced in those who suffered coma, the results suggest that an effect is present across all levels of injury severity with even those with mild injury (GCS 13/14) making five more NART errors on average than those with minor injury (GCS 15). Our findings indicate an average 
difference of 12 IQ points between the estimated premorbid ability of those with a severe injury relative to those with a minor injury. However, in individual cases, the discrepancy between estimated and actual premorbid ability may be even more pronounced. This has considerable implications given the widespread use of the NART and similar measures in clinical practice.

Although the CCRT was also found to be associated with severity of head injury, the association with GCS score was not quite as strong, indicating that the CCRT may be more resistant than the NART to the effects of brain injury. This is consistent with findings that the CCRT is less affected by severity of cognitive impairment than the NART in dementia patients (Conway \& O'Carroll, 1997). It also reflects findings that the reading of single irregular words in isolation is compromised in more cognitively impaired Alzheimer patients (Patterson, Graham, \& Hodges, 1994), whereas contextual priming is relatively preserved (Nebes, 1994; Nebes \& Halligan, 1996). Although the CCRT may be more resistant than the NART(and was preferred by most patients), it also appears to be susceptible to compromise by brain injury.

As these premorbid measures appear to be affected by brain injury, it may be advisable to compare estimates of premorbid intelligence based on the NART, CCRT or WTAR with estimates based upon pre-injury demographics (Crawford \& Allan, 1997; Crawford, Allan, Cochrane, \& Parker, 1990; Crawford, Millar \& Milne, 2001). These demographically derived estimates, together with consideration of injury severity, may assist in identifying instances where NART or CCRT derived estimates are likely to have underestimated true premorbid ability.

\section{References}

Beardsall, L. (1998). Development of the Cambridge Contextual Reading Test for improving the estimation of premorbid verbal intelligence in older persons with dementia. British Journal of Clinical Psychology, 37, 229-240.

Beardsall, L., \& Huppert, F. A. (1994). Improvement in NART word reading in demented and normal older persons using the Cambridge Contextual Reading Test. Journal of Clinical and Experimental Neuropsychology, 16, 232-242.

Conway, S. C., \& O'Carroll, R. E. (1997). An evaluation of the Cambridge Contextual Reading Test (CCRT) in Alzheimer's disease. British Journal of Clinical Psychology, 36, 623-625.

Crawford, J. R., \& Allan, K. M. (1997). Estimating premorbid IQ with demographic variables: Regression equation derived from a UK sample. Clinical Neuropsychologist, 11, 192-197.

Crawford, J. R., Allan, K. M., Cochrane, R. H., \& Parker, D. M. (1990). Assessing the validity of NART-estimated premorbid IQs in the individual case. British Journal of Clinical Psychology, 29, 435-436.

Crawford, J. R., Millar, J., \& Milne, A. B. (2001). Estimating premorbid IQ from demographic variables: A comparison of a regression equation vs. clinical judgement. British Journal of Clinical Psychology, 40, 97-105.

Crawford, J. R., Parker, D. M., \& Besson, J. A. (1988). Estimation of premorbid intelligence in organic conditions. British Journal of Psychiatry, 153, 178-181.

Freeman, J., Godfrey, H. P., Harris, J. K., \& Partridge, F. M. (2001). Utility of a demographic equation in detecting impaired NART performance after TBI. British Journal of Clinical Psychology, 40, 221-224.

Moss, A. R., \& Dowd, T. (1991). Does the NART hold after head injury? A case report. British Journal of Clinical Psychology, 30, 179-180. 
Nebes, R. D. (1994). Contextual facilitation of lexical processing in Alzheimer's disease: Intralexical priming or sentence-level priming? Journal of Clinical and Experimental Neuropsychology, 16, 489-497.

Nebes, R. D., \& Halligan, E. M. (1996). Sentence context influences the interpretation of word meaning by Alzheimer patients. Brain and Language, 54, 233-245.

Nelson, H. E., \& McKenna, P. (1975). The use of current reading ability in the assessment of dementia. British Journal of Social and Clinical Psychology, 14, 259-267.

Nelson, H. E., \& Willison, J. R. (1991). The revised National Adult Reading Test - Test Manual. Windsor, Berks: NFER-NELSON.

O'Carroll, R. (1995). The assessment of premorbid ability: A critical review. Neurocase, 1, 83-89.

O'Carroll, R. E., Moffoot, A., Ebmeier, K. P., \& Goodwin, G. M. (1992). Estimating pre-morbid intellectual ability in the Alcoholic Korsakoff syndrome. Psychological Medicine, 22, 903-909.

Patterson, K., Graham, N., \& Hodges, J. (1994). Reading in dementia of the Alzheimer's type: A preserved ability? Neuropsychology, 8, 395-407.

Teasdale, G. M. (1995). Head injury. Journal of Neurology, Neurosurgery and Psychiatry, 58, 526-539.

Teasdale, G. M., \& Brooks, N. (1985). Traumatic amnesia. In J. Frederiks (Ed.), Handbook of clinical neurology (pp. 185-191). Amsterdam: Elsevier.

Watt, K. J., \& O'Carroll, R. E. (1999). Evaluating methods for estimating premorbid intellectual ability in closed head injury. Journal of Neurology, Neurosurgery and Psychiatry, 66, 474-479.

Received I 2 May 2003; revised version received 19 January 2004 